\title{
AUTHENTICITY IN BUILDING ADJUSTMENT SIMULATION (Case Study: Emergency Room of St. Elizabeth Hospital Semarang, Indonesia)
}

\author{
Sri Hartuti Wahyuningrum ${ }^{1}$, Mustika K Wardhani ${ }^{2 *}$, Robert Rianto Widjaja ${ }^{3}$ \\ ${ }^{1}$ Department of Architecture, Faculty of Engineering, Diponegoro University, \\ Jl. Prof. Sudarto 13, Semarang 50275, INDONESIA \\ ${ }^{2}$ Research Organization of Open Innovation and Collaboration, Ritsumeikan University, \\ 2-150 Iwakurachō, Ibaraki, Osaka 5678570, JAPAN \\ ${ }^{3}$ Faculty of Design and Architecture, Unika Soegijapranata, \\ Jl. Pawiyatan Luhur Sel. IV/1, Semarang 50234, INDONESIA \\ "Corresponding author; Email: mk1698@fc.ritsumei.ac.jp
}

\begin{abstract}
This paper aims to simulate adjustments for new functions in hospitals that respect the authenticity of cultural heritage buildings. The development of heritage buildings should be integrated, especially in adjusting building functions, such as room arrangement. The emergency room is a vital function for hospital services, and consideration is needed to arrange procedures. The research method chosen in this research is descriptive qualitative with a case study in the Magdalena Daeman building St Elizabeth Hospital. Design simulation can be realized by adjusting the standard emergency room requirements into the layout of the building. Additionally, cultural heritage buildings should be maintained to be used in operational functions by carrying out development. This study's results can be a guideline in developing new functions of cultural heritage buildings that meet the conservation technique guidelines.
\end{abstract}

Keywords: Sustainability; hospital; heritage building; design simulation.

\section{INTRODUCTION}

Adaptive reuse gives new life to sites by designing sympathetic changes and additions that allow the site to accommodate new compatible uses and functionality while retaining legacy significance and communicating it to new users (ICOMOS, 2014). Also, Ward (2012) explains that successful adaptive reuse means more than merely recycling a building by increasing its value, use, and performance and acting as a catalyst for urban regeneration. The principle of sustainable design encourages the maximum reuse of existing building components. Restoration of passive aspects of the original design and preservation of the historic plantings and site users' microclimate should be incorporated into adaptive reuse of historical buildings (Fournier \& Zimnicki, 2004). The above arguments can strengthen the hypothesis that adaptive reuse can implement the concept related to flexible hospital development in cultural heritage buildings. Today heritage is usually exhibited, and histories are narrated on the hospital websites. Historical rooms, historical mementos, and even social histories of the institutions also remain very common (Logan et al., 2010).

Many previous studies have found a relationship between the concept of adaptive reuse of historic buildings and their continuity in future planning strategies. Li et al. (2021) stated that the assessment of the adaptive reuse of architectural heritage is a comprehensive multi-interest process that involves not only the maintenance of historical, economic, scientific, and aesthetic values but also includes mid-tolong-term development visions combined with planning strategies. Moreover, the adaptive reuse process procedures must be associated with attentiveness for every feature since it may appear to be of great significance at a later time (Elsorady, 2020). In addition, Adaptive reuse, in line with sustainability principles, is a process of revitalizing or reinventing disused or ineffective existing buildings (including old or historical buildings) for new use, purpose, or function (Mohd Abdullah et al., 2020). Also, (Samadzadehyazdi et al., 2020) stated that the most successful adaptive reuse projects retain a building's heritage significance and add a new layer that provides value for the future.

According to Pilosof \& Ii (2020), many previous studies have investigated hospital flexibility, and few assess how the architectural design strategy-design for unknown functionality versus design for specific functions - impacts the flexibility of the hospital to change over time. This paper aims to simulate adjustments for new functions in hospitals that respect the authenticity of cultural heritage buildings. Adaptation involves changing places to facilitate new uses. 
Adaptive reuse can involve changes and additions to meet contemporary convenience and functional requirements, upgrading a building or site in response to new processes and procedures. The architectural design of cultural heritage buildings must be carried out with care given the building's status as a protected registered building, which has detailed binding arrangements to perform new functions in an existing building. Depending on the specificity of the site, further considerations might include the spatial structures and configurations of the entire site; the relationships between structure, site, and context; views to the site, from, and inside; and the traces of activities, systems, and processes (Heritage Council of NSW, 2019). As a designer, architects must generate the building category for modification, such as rehabilitation, restoration, or retrofitting.

Twentieth-century hospitals have become one of the most challenging aspects of public infrastructure for heritage conservation and a potent case for drawing out the dilemmas inherent in the theme of 'keeping the past public' (Logan et al., 2010). However, The characteristics of good hospital design have been established as much by cultural factors as by medical considerations (Theodore, 2016). Health care facilities are among the most time-sensitive facilities; Changes and development patterns of health facilities over time result from, and are related to, urban spatial transformation processes (Sakallaris et al., 2015). Health care facilities typically develop focusing on functionality, rational composition, and space use (Son \& Yang, 2012). In preparation for providing health services at St. Elisabeth Hospital, several obstacles occurred in the field related to the emergency room standard, which was still not meeting the criteria for hospital buildings (class type B) and (level 3) under government regulations regarding hospital buildings number 30/2019 article 19. The emergency room location is expected to have easy access to public and ambulance routes for emergency purposes. The problem statement in this study arises from the case of emergency room location that uses a part of the cultural heritage building that requires modification in adaptive reuse technique guidelines. The existing building used now is an ordinary inpatient unit, which is different from the basic needs of an emergency room.

The identity and value of cultural heritage buildings are considered the most substantial reasons for adaptation (Yazdani Mehr \& Wilkinson, 2020). The design should implement a strategy that combines the need to reuse and preserve historic buildings of extraordinary value to improve the city's health and quality of life (Cherchi, 2015). Moreover, The design is also oriented towards preserving the historic character and at the same time creating a new image, different from traditional hospitals, so the users will be motivated to enter and feel at home in a relaxed and friendly environment (Cherchi, 2015). Therefore, this study uses a simulation technique by providing an alternative design with an optimal strategy. The research findings and implications can be used by stakeholders (hospital owners and managers) as a guide in developing the use of cultural heritage buildings to meet the technical standard requirements required. In addition, architects can use the results of this study as a guide in implementing new functions in cultural heritage buildings, especially in hospital buildings.

\section{METHODOLOGY}

The research method is chosen to describe the main factors affecting the emergency room design based on health standard requirements and is developed by simulating the possibility of structuring to suit the existing building. The design simulation was chosen because it allows adaptation to existing buildings. In this case, if modifications are needed, these efforts do not eliminate the original character of the existing building. The modification also considers the application of new functions to buildings in cultural heritage buildings based on regulations given by the government and health institutions. The new design must respond to its historical context by understanding and analyzing its character and quality included existing development patterns, critical views, scale, materials, and technique. The process of determining the site's cultural heritage involves a complex medical examination and political histories of the hospital located and in more detail at the architectural histories of the various hospital buildings (Tausky, 2011). Consequently, the design must create new relationships between the building, its neighbors, and its arrangement (NSW, 2005). The guidelines used to implement changes to the function of the building are called retrofitting techniques. The schematic of the research flow is described in the diagram below (See figure 1).

\section{RESULTS AND DISCUSSION}

High-tech medicine will develop faster and more sophisticated the way in the $21^{\text {st }}$ century and will be applied on a critical basis life-saving care and hospitals, as in the provision of emergency care, cancer, and heart attacks treatment (Nagasawa, 2020). Moreover, Adaptive reuse is converting the original function of existing buildings whose services and technology are outdated to a new building purpose for new need to meet the current development (Hasan et al., 2017). 


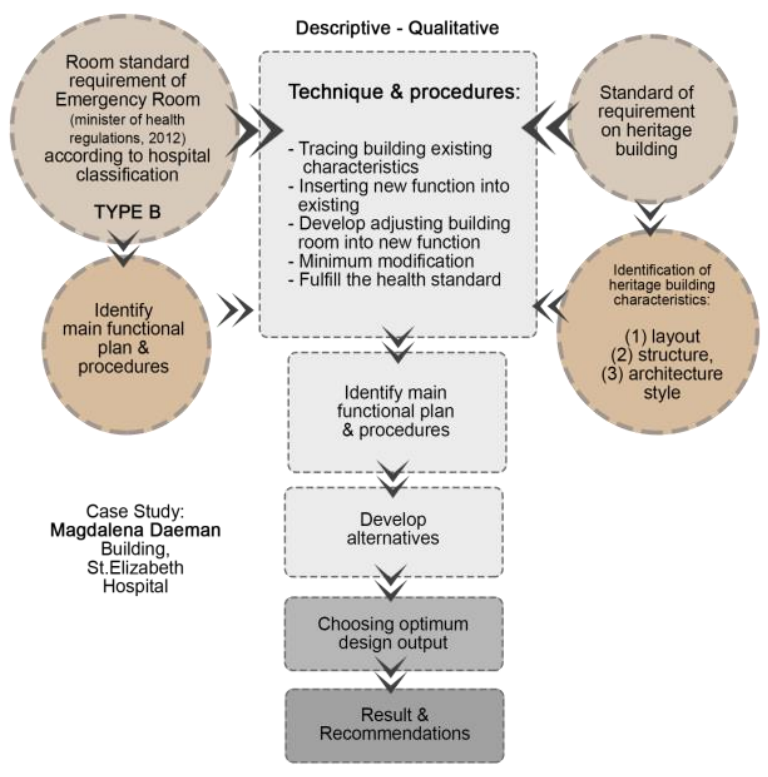

Fig. 1. Research Staging Scheme (Sri Hartuti, 2020)

Based on the problem identified in St. Elisabeth Hospital, it is necessary to relocate the existing emergency room that does not meet the health standard requirements (Hospital type B). This study's hospital emergency unit is equivalent to a Level III emergency service unit consisting of surgeons, internal medicine specialists, pediatricians, and gynecologists. These four specialists must be on site 24 hours a day, seven days a week. General practitioners on duty for 24 hours must have medical qualifications for GELS (general emergency life support) services and ATLS + ACLS $^{1}$ services that can provide resuscitation and stabilization of cases with $\mathrm{ABC}$ (airway, breathing, circulation) problems for definitive therapy. Each hospital is required to have emergency services that have the ability at least: (1) conduct an initial examination of emergency cases; (2) perform resuscitation and stabilization; (3) services in the emergency room of the hospital must be able to provide services 24 hours continuously seven days a week. The urgency of this emergency service unit needs to be considered in developing hospital designs so that activities remain conducive without having to reduce service working hours.

The architectural aspect is critical for deliberating any adaptive reuse decision. Architectural and physical conditions, including façade, building envelope, interior, finishes, building function, and site layout, must be carefully evaluated to determine the necessary interventions and allow spatial flexibility for future use

\footnotetext{
${ }^{1}$ ATLS: Advanced trauma life support; ACLS: Advanced Cardiovascular Life Support
}

(Mohd Abdullah et al., 2020). The results of this study are projections of meeting the standard criteria for an emergency room in the Magdalena Daeman building, which is identified as part of a historic building that still exists in the St. Elizabeth Hospital that needs to be conserved. The principle of conservation follows the conservation in archaeology, with adjustments to fulfill a living heritage. The definition of conservation in cultural heritage buildings used in this research follows regulation number 28 (2002) buildings which refer to statutory regulation number 5 (1992) concerning heritage building as follow: (1) Conservation, activities of conserve, preserve, restoration and also maintaining contextual buildings and sites to fit the reliability of the building into its original function or condition following its period; (2) Restoration, including repair activities, and returning the building to its original form; (3) Rehabilitation, repair or replacement of building components part, building materials and supporting facilities so that the building can be used safely; (4) Maintenance, protecting the reliability of the building including support facilities in order to meet the building required for its function. In this case, the analysis consists of: (1) Design strategy for arranging rooms in Magdalena Daeman Building; (2) Action plan development; (3) Design simulation scenarios as follow:

\section{Analysis of Magdalena Daemen Building Room}

Reuse techniques in cultural heritage building must consider the following relevant matters: (1) The new design is expected to respond to historical contexts through informed understanding and analysis of existing buildings' characteristics and qualities. Consequently, the result of the design will create a new correlation between the building and the environment surroundings. (2) The cultural heritage understanding process from the site, which can be derived from the historical existing hospital complex and also political history on hospital building (Tausky, 2011); (3) Adaptation and retrofitting on the existing building to find out efficiency optimum energy standard shall be noticed carefully at the building sector (UNEP, 2009). The existing site plan condition of St. Elizabeth hospital can be seen in (see figure 2).

Architectural heritage practices are traditionally associated with preservation, rehabilitation, restoration, and reconstruction. Therefore, promising approaches to adaptive reuse that contain standards and guidelines can be applied and developed during a preservation project (Li, Zhao, Huang, \& Law, 2021). The preservation of cultural heritage buildings is part of preserving the living heritage from an artistic, 


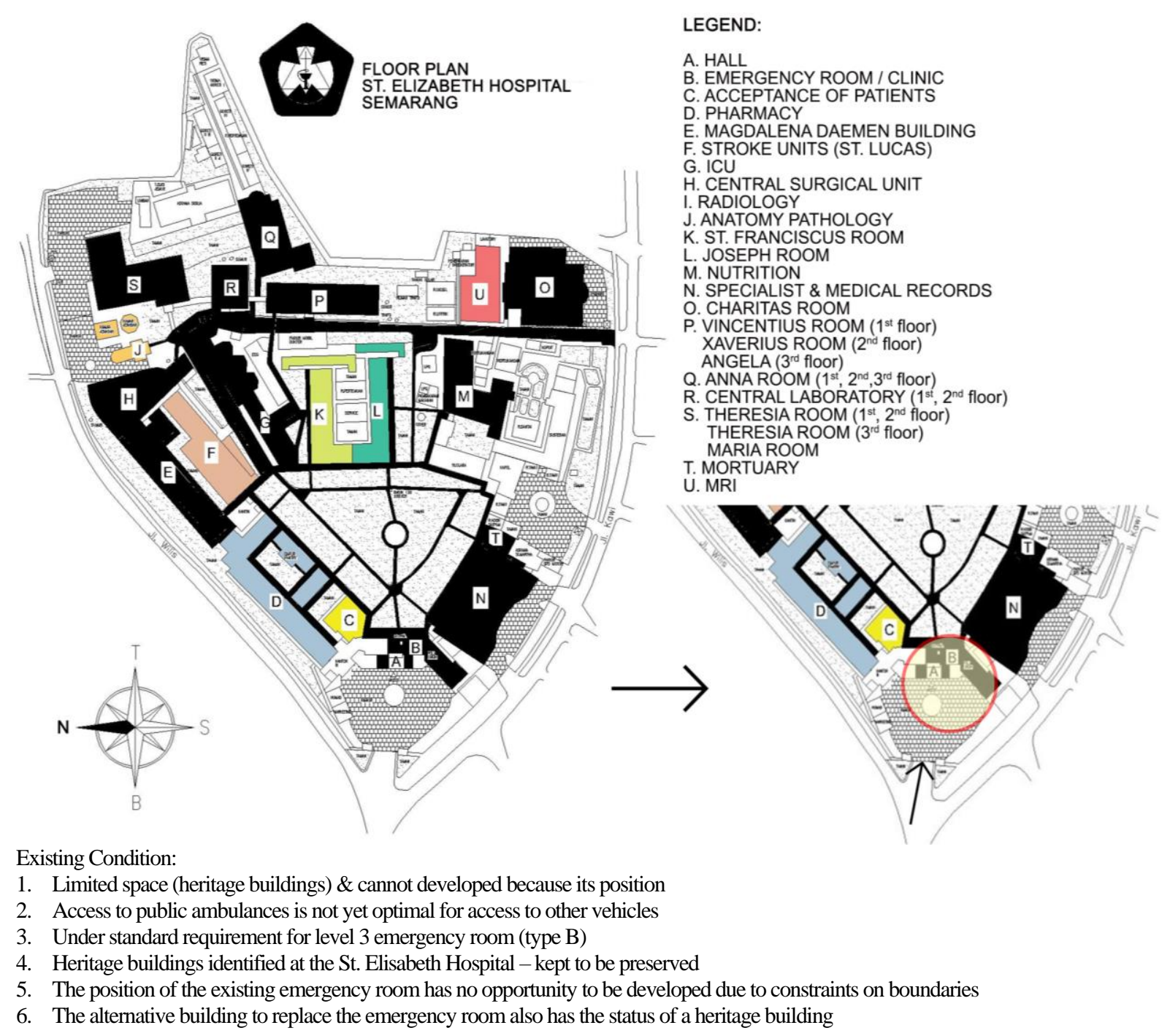

Fig. 2. Site plan of St. Elisabeth Hospital \& Existing building of emergency room - the available space is limited and does not meet the requirements of technical standards (Sri Hartuti, 2020)

economic, social, and scientific period. According to the guidelines for the preservation of cultural heritage buildings as follows: (1) Maintain its original form so that the characteristics of the building affected by the building can be identified; (2) The minimum added value of new structural aesthetics and information is retained not to be changed or reduced; (3) Replacement of new ornaments must be similar to existing ornaments; (4) The original material and the substitute must be the same; (5) The shape of the roof, windows, and doors, exterior, and interior, cannot be changed; (6) New buildings are not permitted at that location unless previous archaeological excavations have been carried out, and the results are also declared to have no archaeological significance; (7) The use of buildings after rehabilitation or restoration must consider to supporting activities. The existing conditions of Daemen Magdalena Building, which will be used as an emergency room for its development, can be explained as follows figure 3 .

According to the health standard requirement for emergency room installation (Purwanto \& Soliha, 2017), technical standards cover at least the provision of (1) Based on the classification of level 3 emergency services in type B hospitals; (2) Standard level 3 can accommodate the following services: (a) Diagnostic and management of cases A, B, C with complete equipment including ventilators; (b) Disability assessment, Drug use, Electrocardiogram (ECG) and Defribilator; (c) High Care Unit (HCU) or Resuscitation; (b) Emergency surgery. Furthermore, in the process of identifying the characteristics of Magdalena Daemen Building, it can be seen that certain types of building layout can be identified as open space types surrounded by the configuration of the building mass (see figure 4). 

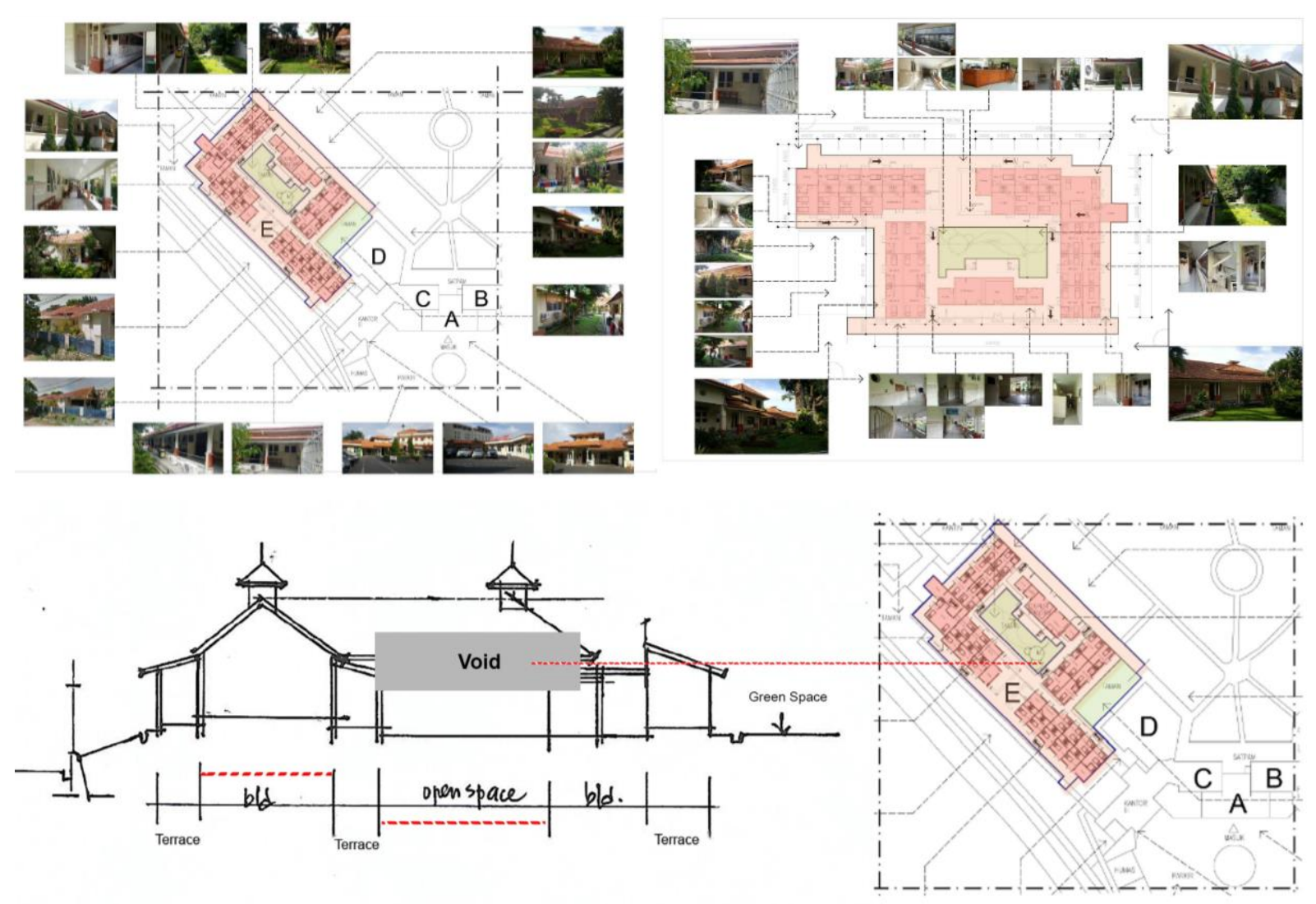

Fig. 3. (a) Position of Magdalena Daemen building and its surrounding; (b) Detail of existing of Magdalena Daemen building (source: data survey, 2020)

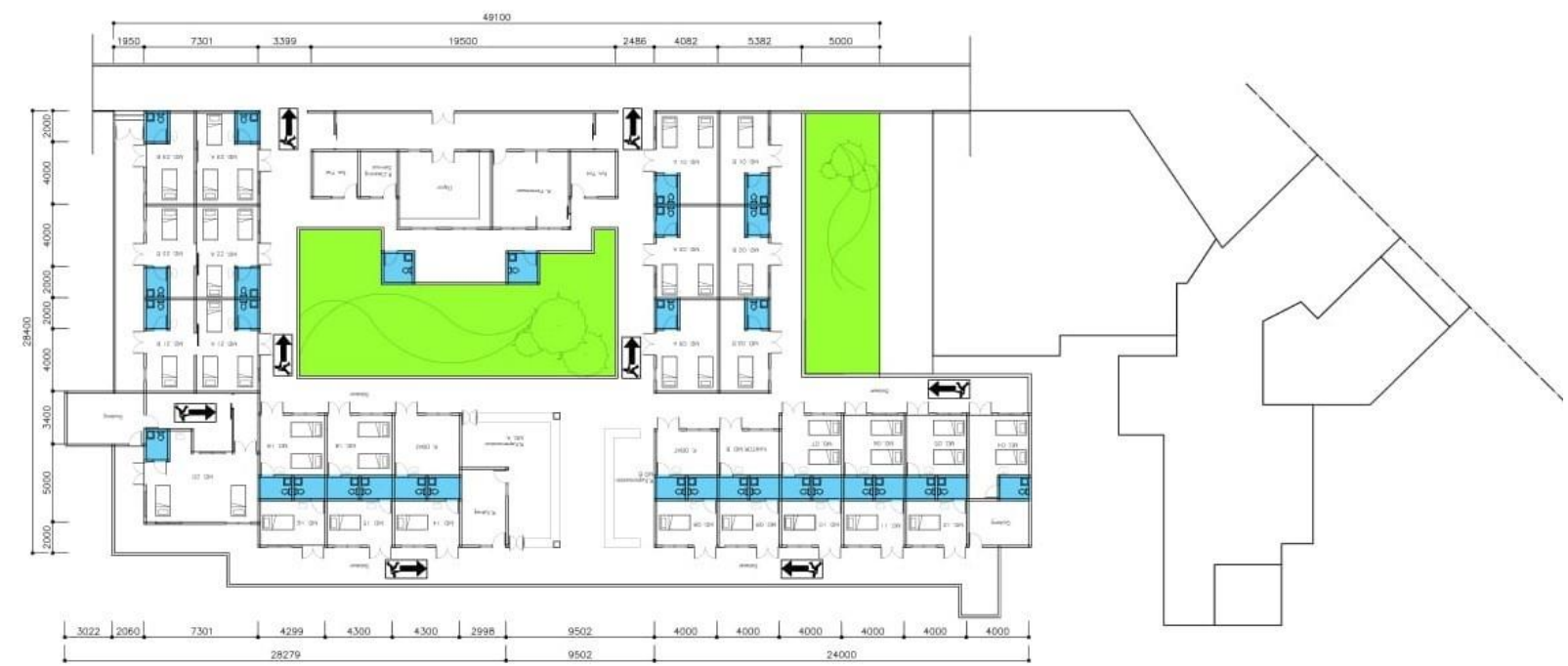

Fig. 4. The existing plan of Magdalena Daemen Building - has an open space in the middle of the building mass configuration (source: data survey, 2020)

\section{Development of Action Plan}

In the context of appropriate uses of the heritage building, depending on the place condition, further consideration will include spacial structure and configuration related to the site, the relation between the structures, site, and context, view to, from and inside, activity traces, system and its process (Heritage Council of NSW, 2019). However, because attention was focused on the healing environment's importance, the medical space underwent internal and external spatial transformations (Jeong, 2019). In addition, Samadzadehyazdi et al. (2020) stated that the three aspects of conceptual, material and aesthetic authenti- 
city are primarily considered in the conservation process, revealing the true nature of heritage. Adaptations made to facilitate new uses may include installation and addition to fulfill user comfort and function. It is hoped that building quality or site response from reuse adaptation processes and procedures will give new life to the site or build through sympathetic additions. In working in the field, sometimes it will cause problems in adjusting the plan for emergency room design development into the existing building. A compact room arrangement is needed in the emergency room because of the systemic operational procedures for health services. Based on the analysis above, it can be determined that an action plan can be developed as a guide in terms of development, especially for the preparation of a new functional spatial plan (see table 1).

For an example of a design simulation in dealing with the problem of preparing an open space to facilitate the control and operation of emergency procedures in the emergency units, the authors try to adopting the transformation of the Great Court of British Museum in London from open space into the largest covered square as a precedent (The British Museum, 2020). A roofing system covering the open courtyard and using 3312 uniquely shaped panels of glass covered at least two acres and became the centerpiece of the museum. The purpose of covering a large courtyard is to create a comfortable space and integrate the rooms around the courtyard, which can be used in many developed activities in the museum. This precedent can be used to address a similar problem at the Magdalena Daemen Building, which requires an open space for observation rooms in emergency units. The similarity between these two cases is mainly in the concept of covering with a new roof system to create interior space from the open space yard. For details on the concept process of the roof covering system at the British Museum, see below (Figure 5).

Table 1: Development of Action Plan

\begin{tabular}{|c|c|c|c|c|}
\hline No & Problems & Existing & Criteria & Action Plan \\
\hline 1. & $\begin{array}{l}\text { ER } \\
\text { Positions }\end{array}$ & $\begin{array}{l}\text { In front of the area of St. } \\
\text { Elisabeth Hospital, the } \\
\text { access still use the same } \\
\text { access for public access }\end{array}$ & $\begin{array}{l}\text { The access shall be in the front of } \\
\text { the hospital but separated from } \\
\text { public access }\end{array}$ & $\begin{array}{l}\text { Emergency room access is } \\
\text { separated from public access } \\
\text { but still in the front area of the } \\
\text { hospital }\end{array}$ \\
\hline 2. & $\begin{array}{l}\text { ER } \\
\text { Size }\end{array}$ & $\begin{array}{l}\text { Due to the standard } \\
\text { requirement size of } \\
\text { Emergency room existing } \\
\text { is too tiny so can not } \\
\text { provide the required } \\
\text { services as needed or } \\
\text { fulfill the standard } \\
\text { requirements }\end{array}$ & $\begin{array}{l}\text { The room shall fulfill at least the } \\
\text { size of the emergency room needed, } \\
\text { as mentioned in the standard } \\
\text { requirements. Including providing: } \\
\text { decontamination area, triage, } \\
\text { irregular emergency condition and } \\
\text { also fulfill the Level III emergency } \\
\text { room for the hospital (type B) }\end{array}$ & $\begin{array}{l}\text { Need more prominent space } \\
\text { for accomodating new } \\
\text { emergency room }\end{array}$ \\
\hline 3. & $\begin{array}{l}\text { Room } \\
\text { Capacity }\end{array}$ & $\begin{array}{l}\text { Not fulfill yet for standard } \\
\text { requirement }\end{array}$ & $\begin{array}{l}\text { Development in the existing area is } \\
\text { complex because space is limit, and } \\
\text { the building is already blocked by } \\
\text { other functional section (outpatient } \\
\text { department and medical rehab) }\end{array}$ & $\begin{array}{l}\text { Confirmation that the space } \\
\text { available for accomodating } \\
\text { new emergency room is } \\
\text { Magdalena Daemen building, } \\
\text { which is positioned in the } \\
\text { opposite of existing building }\end{array}$ \\
\hline 4. & $\begin{array}{l}\text { Vertical } \\
\text { building } \\
\text { purposes } \\
\text { (Possibility) }\end{array}$ & $\begin{array}{l}\text { Not applicable due to the } \\
\text { existing building and } \\
\text { proposed building for the } \\
\text { emergency room have } \\
\text { heritage building status. }\end{array}$ & $\begin{array}{l}\text { To ensure the space availability is } \\
\text { enough to accommodate building } \\
\text { size need }\end{array}$ & $\begin{array}{l}\text { To find possible building } \\
\text { available (such as Magdalena } \\
\text { Daemen) for alternative } \\
\text { building for the new } \\
\text { emergency room }\end{array}$ \\
\hline 5. & $\begin{array}{l}\text { Heritage } \\
\text { Building } \\
\text { Relation }\end{array}$ & $\begin{array}{l}\text { Part of St. Elisabeth } \\
\text { Hospital have heritage } \\
\text { building status (but not } \\
\text { declare precisely the } \\
\text { building items) }\end{array}$ & $\begin{array}{l}\text { Need more data for the guidance of } \\
\text { boundaries and declaration of the } \\
\text { heritage building precisely. }\end{array}$ & Need further documentation \\
\hline
\end{tabular}




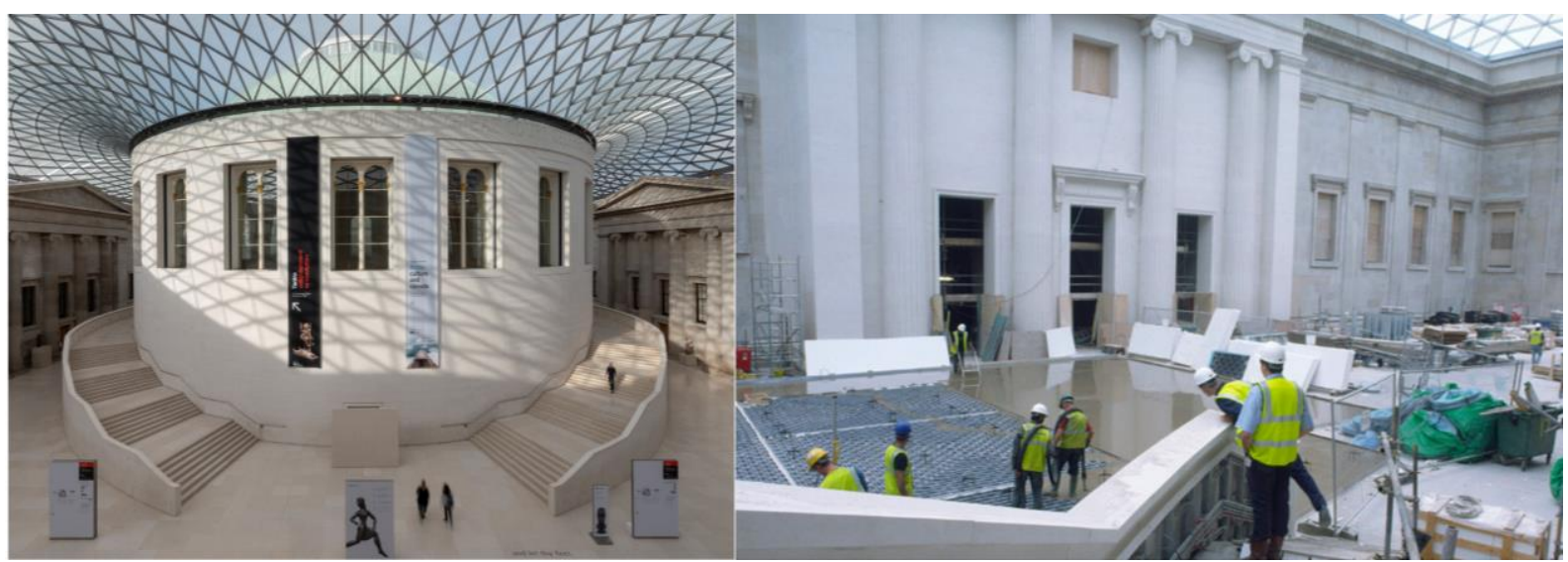

Fig. 5. The result of covering great court at British Museum London. Source: (British Museum, 2020)

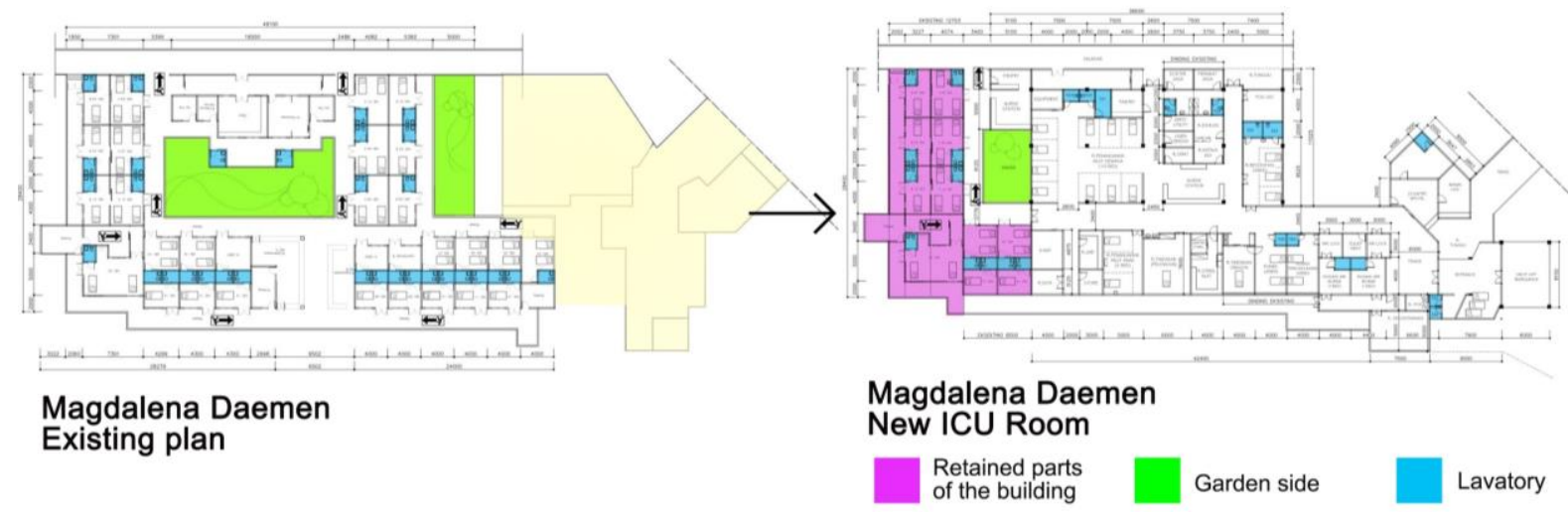

Fig. 6. Planning the layout of the new emergency room into the Magdalena Daemen building as an effort to transform from regular inpatient units into a new function as an ER unit (source: Sri Hartuti, 2020)

The concept of the plan is to develop space by covering open space with a new roofing system without leaving the characteristic of building existing, and 'feels' of open spaces can be a trace in remain. The existing condition at Magdalena Daemen notices that open space needs to be transformed and covered by the roofing system to achieve a new wide-open span of room for the observation area directly faced to the nurse station. Follow the room configuration standard in emergency room installation. The observation area is the section for the patient is monitored and observed intensively by nurses and doctors. The configuration of the bed position is also essential for the ease of nurses making visual contact to monitor patients. Based on the above guidelines, the possibilities of space development are as follows (see figure 7).

Roof system techniques can still be developed in these conditions. The choice of roofing material to accommodate patients should provide situational support conditions not to disturb the patient by visual glare. Room temperature inconvenience caused by the wrong choice of roofing materials and the system should be avoided. The use of glass panels for roof components is not recommended, so to provide natural light insertion, we must consider indirect openings to provide natural light for the new enclosing space.

\section{Design Simulation Scenario}

An integrated simulation between requirements will include the following procedures such as (1) Integrating this area as an entrance (triage purpose) and use it as a new entrance to the emergency room, including removing the existing building (main facade) for new access to the ambulance; (2) Developing open spaces area into a new space but still maintaining the existing characteristics (changing outdoor to indoor); (3) Rearranging the space for new functions, including developing particular building finishes; (4) Incorporating a new roof structure to cover open spaces with minimal intervention to provide new spaces to accommodate emergency room layouts; (5) Maintain the characteristics of the open space so as not to damage the visuality of the existing features. The results can be seen below (see figure 8). 


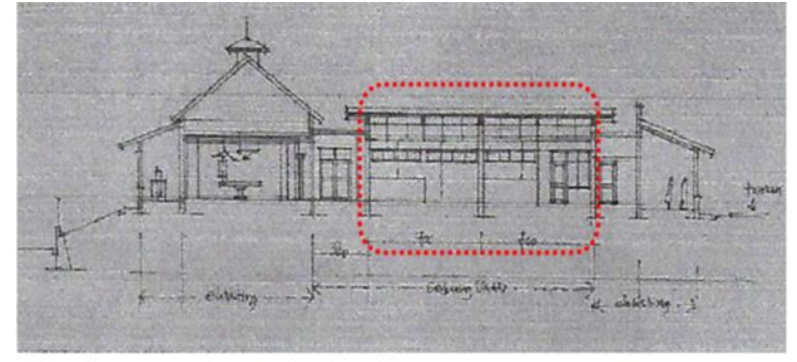

1. Use of open space to increase the volume of space

Maintain the characteristics of the building (roof configuration) of the mass of the building

3. The additional space is accomplished by minimizing the disruption of the new roof insertion form

Fig. 9. Scenarios for developing Magdalena Daemen for a new function as an emergency room by covering open spaces with a roof system to provide an observation room with comprehensive openness(source: Sri Hartuti, 2020)

The alternative chosen for simulation is using a concrete slab with a relatively wide span at eight (8) meters wide, also provides windows for inserting natural light in an indirect position and set at the upper of the existing roof. This alternative has the advantage, due to wide-open space, we can divide it into two (2) spans that consist of one (1) is seven (7) meters and the other is eight (8) meters. Furthermore, the availability of columns in this position relatively does not disturb the visual clearance for this area. The adjustments to the existing mass are as follows (see figure 10).

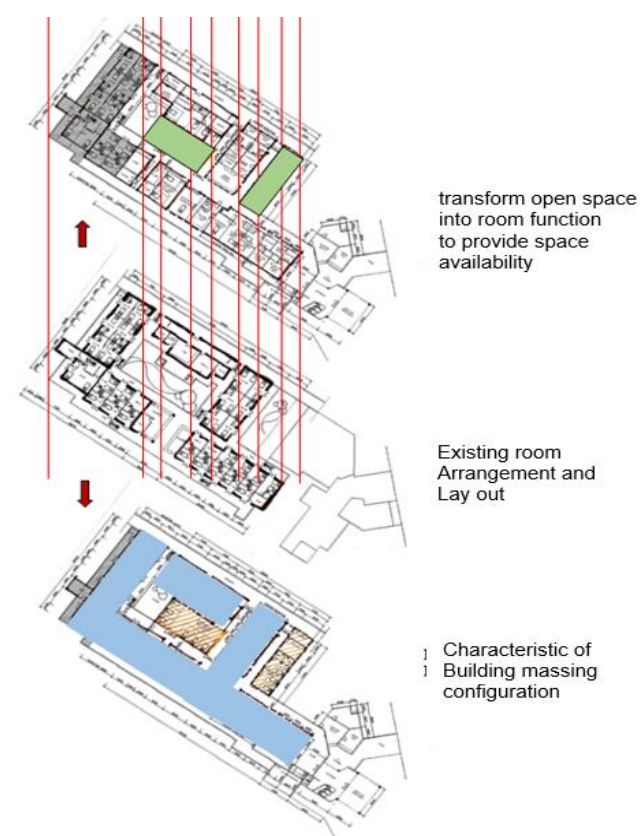

Fig. 11. Guidelines of massing transformation give guidance for recognizing existing massing. Assist for covering open space but still indicate the existing massing outline (source: Sri Hartuti, 2020)

As mentioned in the introduction section, this study aims to explain the framework for the adjustment of hospitals established on historical sites to use adaptive reuse strategies in planning. Thus, the adjustments made to the mass configuration of Magdalena Daemen building in principle do not change its layout characteristics. The changes that occur are more emphasized on the transformation of open space into a functional space that remains open by being converted into an observation room function. Creating a healing environment within the scope of medical space included in historical buildings gives new meaning to cultural heritage through its sustainable use (Jeong, 2019). A positive atmosphere can also be achieved by using sensitive colors, light, aroma, texture, and sound by integrating art, interior design, and landscape design (Nagasawa, 2020). The orientation of other spaces is maintained so that the character in the open space area also remains the same, but the open space itself is converted into a functional space. Efforts are made not to leave the lighting character in this area maintained by providing indirect natural lighting to the converted area.

\section{CONCLUSION}

Yazdani Mehr \& Wilkinson (2020) stated that genius loci and authenticity are frequently seen as separate concepts in adaptive reuse. Genius loci are described as 'spirit of place' while authenticity is described as being original and representing specific characteristics of a heritage building. The adaptive reuse concept has significant support as a positive strategy to make the built environment more sustainable and represent specific characteristics with their own 'sense of place'. Adaptive reuse increases the long-term usefulness of a building and, therefore, is a more sustainable option than demolition and rebuilding (Ijla \& Broström, 2015). In providing rooms with new functions in the hospital, architects must consider the availability of space to meet the required capacity and understand the building's characteristics, especially in terms of heritage sites. In introducing new elements into heritage buildings, architects as designers also need experience in structural installation techniques. Several stages that can be considered in the design development with case studies of emergency rooms in historic buildings are: (1) analysis of the character of historical buildings used as emergency rooms; (2) development of an action plan; and (3) design simulation scenarios. From the results of the study, the findings from the analysis can be concluded as follows:

1. Meeting the building capacity or the availability of space to accommodate new functions

2. Rearrangement of the layout of the existing building is possible but still follows the standard 
provisions for the development of cultural heritage buildings on new functions (retrofitting)

3. To carry out development. It is necessary to determine the existing conditions and characteristics (probability of development), trace the characteristics and documents of the existing buildings, insert new layouts or functions and modify all possible minimum interventions.

4. Relevant in selecting structural systems for new functions but without interfering with existing ones structure.

According to Pilosof \& Ii (2020), Hospitals need to be designed to suit specific functions optimally and remain as small as possible to accommodate future functional changes. Flexibility is often a requirement that must be built into the organization's plans to anticipate growth and facility changes. In other words, the hospital complex consists of not only one building but a network of buildings with various structures and materials, each of which has different standards and technical conditions (Nagasawa, 2020). The novelty of this study indicated that to make adjustments to new functions that respect the authenticity of the heritage buildings, it should be considering adjustments of the space requirements in the future, rearranging the spatial layout with the concept of retrofitting, paying attention to the characteristics of existing buildings, and choosing a structural system that is relevant. The limitation of this research only focuses on the emergency room building, which is part of the heritage building. The focus of the design simulation is only on spatial planning and its interaction with the possible open space around it for easy patient mobility. Thus, the adjustment of space requirements seeks to meet the standard of type $B$ hospital health services. For further action, the development plan is expected to provide an alternative to the new building structure added while maintaining the concept of insertion of new functions conveyed. It is also developing research relevant to the implementation of finishing materials, new mechanical and electrical installations.

\section{ACKNOWLEDGMENT}

Thanks to the Faculty of Engineering Diponegoro University for providing strategic research grants in the academic year 2020 based on the letter of statement number 145/UN7.5.3.2/HK/2020.

\section{REFERENCES}

British Museum. (2020). Retrieved from blog.britishmuseum.org on 1 June 2021
Cherchi, P. F. (2015). Adaptive Reuse of Abandoned Monumental Buildings as a Strategy for Urban Liveability. Athens Journal of Architecture, 1(4), 253-270. https://doi.org/10.30958/aja.1-4-1

Elsorady, D. A. (2020). Adaptive Reuse Decision Making of a Heritage Building Antoniadis Palace, Egypt. International Journal of Architectural Heritage, 14(5), 658-677. https://doi.org/ 10.1080/15583058.2018.1558313

Fournier, F. D., \& Zimnicki, K. (2004). Integrating Sustainable Design Principles into the Adaptive Reuse of Historical Properties. Washington, DC: Construction Engineering Research Laboratory, $1-60$

Hasan, H. S. M., Wahab, L. A., \& Ismail, D. (2017). A Review of Authenticity in Adaptive Reuse of Heritage Buildings in. Proceedings of International Conference on Architecture 2017 (ICRP-AVAN), 2017(2016), 59-63.

Heritage Council of NSW. (2019). Design Guide for Heritage (02), 1-70.

Ijla, A., \& Broström, T. (2015). The Sustainable Viability of Adaptive Reuse of Historic Buildings: the experiences of Two World Heritage Old Cities; Bethlehem in Palestine and Visby in Sweden. 2(4), 52-66.

Jeong, T. J. (2019). Sustainable use of cultural heritage in the formation of healing environments: A case study of a healthcare facility on a historic urban site. Sustainability (Switzerland), 11(7). https://doi.org/10.3390/su11071866

Li, Y., Zhao, L., Huang, J., \& Law, A. (2021). Research frameworks, methodologies, and assessment methods concerning the adaptive reuse of architectural heritage: a review. Built Heritage, 5(1). https://doi.org/10.1186/s43238-021-00025$\mathrm{X}$

Logan, C., Goad, P., Willis, J., Logan, C., \& Goad, P. (2010). Modern hospitals as historic places Modern hospitals as historic places. 2365. https://doi.org/10.1080/13602365.2010.519952

Mohd Abdullah, M. S., Suratkon, A., \& Syed Mohamad, S. B. H. (2020). Criteria for adaptive reuse of heritage shop houses towards sustainable urban development. International Journal of Sustainable Construction Engineering and Technology, 11(1), 42-52. https://doi.org/10. 30880/ijscet.2020.11.01.005

Nagasawa, Y. (2020). Global Hospitals in 2050 - A review of the historical development of hospital building studies from a global perspective. 3(1). https://doi.org/10.1002/2475-8876.12131

NSW, H. C. (2005). Design in Context: Guidelines for Infill Development in the Historic Environ- 
ment, NSW Heritage Office \& Royal Australian Institute of Architects NSW Chapter.

Pilosof, N. P., \& Ii, M. (2020). Building for Change: Comparative Case Study of Hospital Architecture. 1-14. https://doi.org/10.1177/1937586720 927026

Purwanto, U., \& Soliha, E. (2017). Influence of City Branding, Brand Identity and Brand Image on Visiting Decision To Kota Pekalongan. Jurnal Bisnis Dan Manajemen, 18(02), 34-45. https://doi.org/10.24198/jbm.v18i1.40

Regulation Number 28 year 2002

Regulation number 5 year 1992

Sakallaris, B. R., Macallister, L., Voss, M., Smith, K., \& Jonas, W. (2015). Optimal healing environments. 40-45. https://doi.org/10.7453/gahmj. 2015.043

Samadzadehyazdi, S., Ansari, M., Mahdavinejad, M., \& Bemaninan, M. (2020). Significance of authenticity: learning from best practice of adaptive reuse in the industrial heritage of Iran. International Journal of Architectural Heritage, 14(3), 329-344. https://doi.org/10.1080/155830 58.2018 .1542466
Son, J. H., \& Yang, N. W. (2012). A Study on characteristics of considering healing environmental concept in domestic healthcare architectures schematic design - Focusing on the prizewinner of healthcare architecture design competition since 2000. Arch. Res., (28), 125-132.

Tausky, N. Z. (2011). Cultural Heritage Assessment: Buildings In The South Street Hospital Complex London, Ontario.

Theodore, D. (2016). Better design, better hospitals. https://doi.org/DOI:10.1503/cmaj.151228

Truscott, M. C. (2014). Burra Charter: The Australia ICOMOS Charter for Places of Cultural Significance (1999). Encyclopedia of Global Archaeology, 1078-1082. https://doi.org/10.1007/978-14419-0465-2_1046

UNEP. (2009). Buildings and Climate Change: Summary for Decision-Makers. UNEP publications.

Yazdani Mehr, S., \& Wilkinson, S. (2020). The importance of place and authenticity in adaptive reuse of heritage buildings. International Journal of Building Pathology and Adaptation, 38(5), 689-701. https://doi.org/10.1108/IJBPA01-2020-0005 